\title{
What is (Correct) Practical Reasoning?
}

\author{
Julian Fink
}

Received: 19 June 2012 / Accepted: 3 May 2013

(C) Springer Science+Business Media Dordrecht 2013

\begin{abstract}
This paper argues that practical reasoning is a mental process which leads a person from a set of existent mental states to an intention. In Section 1, I defend this view against two other proposals according to which practical reasoning either concludes in an action itself or in a normative belief. Section 2 discusses the correctness of practical reasoning and explains how the correctness of instrumental reasoning can be explained by the logical relations that hold between the contents of the mental states. In Section 3, I explore the correctness of normative practical reasoning. I conclude with the sceptical view that correct practical reasoning cannot require us to intend to do what we believe we ought to do.
\end{abstract}

Keywords Practical reasoning · Normative reasoning · Instrumental reasoning · Correct reasoning

\section{When is Reasoning Practical?}

It is commonly accepted that reasoning is a mental process which leads a person from her existing mental states to a new mental state (Broome 2000, p. 195). Since Aristotle, philosophers have distinguished practical from theoretical reasoning. Theoretical reasoning is normally taken to lead to a belief. For practical reasoning, however, the answer is not so unequivocal. I try to set out an answer below.

Before I can answer the question of when reasoning is practical, I need to make a preliminary assumption. I will assume that "[a] practical inference is characterised by having an appropriate practical conclusion" (Raz 1978, p. 5). I think this assumption is justified, because practical reasoning is reasoning towards an action. That is to say, an action, an intention to act, or the description of an action will be somehow involved in the conclusion of practical reasoning. Further, I assume that practical 
reasoning does not presuppose any restrictions on the nature of the premises which can constitute a practical inference.

Joseph Raz offers three characterisations of which nature the conclusion of a piece of reasoning must be in order to count as practical reasoning:

The extant explanations fall into three main types; (a) the view that the conclusion is an action or an attempt, (b) that it is (the formation of) an intention or an expression of an intention, (c) that it is a deontic statement, for example that the agent ought to perform a certain action. (Raz 1978, p. 5)

In the following, I defend the view that reasoning is practical if and only if it leads to (the formation of) an intention. My argument for this view will be mainly negative in that I deny that reasoning can conclude in an action itself. Furthermore, if reasoning concludes in a deontic belief I argue that it is not really practical. ${ }^{1}$

Commonly, Aristotle is associated with the view that practical reasoning concludes in an act itself. ${ }^{2}$ However, in De Motu Animalium, Aristotle himself provides us with sufficient reasons to doubt this view.

[In practical reasoning] the conclusion which results from the two premises is [an] action. For example, whenever someone thinks that every man should take walks, and that he is a man, at once he takes a walk. Or if he thinks that no man should take a walk now, and that he is a man, at once he remains at rest. And he does both of these things, if nothing prevents or compels him. I should make something good; a house is something good. At once he makes a house. I need covering; a cloak is a covering. I need a cloak. What I need, I have to make; I need a cloak. I have to make a cloak. And the conclusion, the "I have to make a cloak", is an action. (Aristotle $\left(1978,701^{\mathrm{a}} 7 \mathrm{ff}\right.$ )

Although Aristotle asserts that practical reasoning results directly in an action, his statement is ambiguous. First, he calls "I have to make a cloak" the conclusion of practical reasoning, which evidently is not an action but a belief, though he calls it an action. Yet "I have to make a cloak" only includes the description of an action, i.e., "making a cloak", which, in Aristotle's example, the reasoner takes to be necessary or obligatory. As Anthony Kenny rightly observes, this "calls [into] question the sense of [the] word [action] in the other passages" Kenny (1975, p. 97). Second, Aristotle himself denies that the conclusion of practical reasoning must always be an action. Something (say an external obstruction) may prevent the performance of the action after the reasoning process has taken place. Thus, in this case, the reasoning process has a conclusion, without, however, the action occurring. It follows that the action

\footnotetext{
${ }^{1}$ Strictly speaking, Raz's proposal cannot be entirely correct in suggesting that the conclusion of practical reasoning may be a "deontic statement". A deontic statement may be the content of the conclusion of a practical inference - in which case the conclusion of a practical inference is a deontic or normative belief. Thus, I will assume that Raz's third proposal (c) is that the conclusion of a piece of practical reasoning is a deontic or normative belief.

2 "The most exciting thing which Aristotle has to say about the topic is that a practical inference leads up to or ends in an action, that its conclusion is an action" (von Wright 1978, p. 46). Note, however, that my definition of reasoning at the beginning of this section implicitly excludes the view that reasoning concludes directly in a physical act. I said that reasoning is a mental process which takes place between mental states. Since acquiring a new mental state is clearly not an (physical) action, reasoning cannot end in an (physical) action. However, I think this is not a disadvantage of my definition; to suppose that reasoning can directly conclude in an action is a very implausible view as I argue below.
} 
itself is not the conclusion of practical reasoning, because in this case there is a conclusion but no action. (I shall return to this point below.)

Nonetheless, Aristotle seems to argue that if there is no external obstruction, practical reasoning necessitates an action. For example, if you ${ }^{3}$ believe that every person should take walks and that you are a person, unless something (external) hinders you, you will take a walk. But this is also implausible. Suppose that a moment before you start walking the phone rings or you decide to stay at home or you simply forget that you intend to take a walk (Vogler 2001, p. 448). None of these events represent an external obstruction to you taking a walk. Nevertheless, it seems dubious to think that in this situation you actually will take a walk. Therefore, I think, your taking a walk is not necessitated by practical reasoning, even if nothing externally prevents you from walking.

A further flaw of this view is that it excludes possible internal defects which can distract the reasoning process. It implies that if you reason correctly and there are no external obstructions, then your action will be necessitated by your reasoning. But conceivably, there may be internal obstructions (apart from incorrect reasoning) which "hinder" you from performing the action that correct reasoning requires of you (such as forgetfulness, depression, inability, weakness of the will, etc.) (cf., Raz 1978 , p. 5). The view that reasoning necessitates an action is therefore unable to express the difference between failure to act due to flawed reasoning and failure to act due to other (internal) defects (cf., Raz 1978, pp. 5-6).

I argued above that the action itself cannot be the conclusion of practical reasoning. Sometimes the reasoning process has a conclusion without an action occurring. This implies that the conclusion state of practical reasoning must be such as that it likely to cause an action without requiring further reasoning activity. ${ }^{4}$ Practical reasoning must lead to a mental state which is likely (given no external and internal obstructions) to cause an action. Indisputably, intentions qualify as such states. Intentions are mental states which have the propensity to directly cause you to do what you intend. ${ }^{5}$ In addition, an intention does not seem to require further reasoning to cause you to act. Therefore, Raz's second proposal (i.e., the conclusion of practical reasoning is an intention) seems to be a good candidate to distinguish practical reasoning from other types of reasoning.

Consequently, the question remaining is whether a normative belief also has the required property to cause actions without requiring further reasoning. ${ }^{6}$ Unlike nonmental acts, normative beliefs (as well as intentions) are clearly possible conclusions of a reasoning process. Reasoning can lead to an intention as well as to a

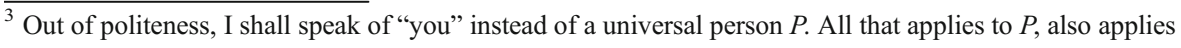
to you.

${ }^{4}$ This state cannot require any further reasoning to cause an action, because then it would not qualify as the conclusion but rather as a (further) premise of the reasoning process.

${ }^{5}$ More precisely, intentions are mental events which cause you to act in a certain way in particular trigger circumstances. A distinctive property of an intention is that it does not require further reasoning to cause an action (i.e., reasoning is not a part of the trigger circumstances)(cf., Lewis 1989, pp. 116-7).

${ }^{6}$ Raz argues that both mental states, i.e. an intention and a normative belief, are likely to cause an action. "Cleary, an intention leads or tends to lead to an action and so do one's beliefs as to what one ought to do" (Raz 1978, p. 5). However, the real question at stake is whether normative beliefs, like intentions, lead to an action without requiring further reasoning.
} 
normative belief. However, I doubt that a normative belief with the content "I ought to $\phi$ " possesses the required property to cause me to $\phi$ without further reasoning.

This is so because for a belief "I ought to $\phi$ " to have this property, it must either be (i) identical with my intention to $\phi$ or (ii) necessarily lead to an intention to $\phi$. In short, a normative belief must either be an intention (or an expression of it) or lead to an intention simpliciter (cf., Smith 1994, p. 61). Both views represent a version of belief internalism which claims that there is a necessary connection between believing what you ought to do and intending (cf., Parfit 1997; Broome 1997; Smith 1994). But I think we can happily reject this view, or so I will assume (cf., Broome 1997, p. 139). Both proposals fail to leave enough room for explaining apparent phenomena such as weakness of the will and other internal defects which leave your normative judgments intact, but hinder you from forming an intention upon your judgments. ${ }^{7}$ This implies that the connection between a normative judgment and an intention ought to be construed as a defeasible one. This can be done by making the transition from a normative belief to an intention dependant on the agent's rationality. If a person believes that she ought to $\phi$, then she intends to $\phi$ or she is practically irrational (cf., Smith 1994, p. 61). An agent may sincerely believe that she ought to $\phi$, without necessarily intending (or being otherwise motivated) to $\phi$.

However, the fact that the connection between a normative judgment and an intention is defeasible implies that reasoning which concludes in a normative belief may require further steps of reasoning to become really practical and to cause an action. Thus, normative beliefs themselves are not fully or truly practical. Reasoning might end in a normative judgment which leads to an intention, but this step will be accompanied by further reasoning to become truly practical. ${ }^{8}$ In consequence, normative beliefs do not qualify as the conclusion of practical reasoning. Reasoning, therefore, is practical if and only if it concludes in an intention.

I think this view has many advantages. First, it is consistent with an entire set of arguments which imply that practical reasoning does not always lead to an action. Second, it is also consistent with the fact that the conclusion of practical reasoning is often drawn long before the action occurs. "[T]he conclusion of a piece of practical reasoning may be a decision about the future, which cannot be carried out until the time comes" Kenny (1975, pp. 97-8). In the remainder of this essay I shall only be concerned with reasoning which leads to an intention.

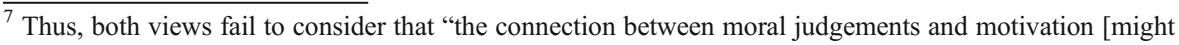
be disconnected by] practical irrationalities of various kinds [...] [which] can leave someone's evaluative outlook intact while removing their motivations altogether" (Smith 1994, pp. 120-1). Also, cf. Stocker (1979, p. 774).

${ }^{8}$ In Section 3 I discuss the proposal that correct practical reasoning leads you from your belief that you ought to $\phi$ to your intention to $\phi$ and thus closes the gap between normative beliefs and intention. But in this case, the normative belief is not the conclusion but the premise of the reasoning process.

${ }^{9}$ Cf., Raz (1978, p. 6), Kenny (1975, pp. 97-8). Note that according to the view that practical reasoning concludes in an action, the conclusion of practical reasoning can only be drawn at or just a moment before the action occurs. However, intuitively it seems clear that rational decision making can take place long before the time of the action.
} 


\section{Correct Practical Reasoning}

In the last section, I concluded that reasoning is practical if and only if it concludes in an intention. But, in fact, this is not entirely correct. Since I defined "reasoning" as a mental process which takes you from one mental state to another, any mental process which leads to an intention could be called "practical reasoning". However, noticing that it rains, then contemplating about Hamlet's intentions, then intending to prepare some dinner presumably does not count as a genuine episode of practical reasoning (Vogler 2001, p. 447). To do so, it seems appealing to say that the premise-states of practical inference must stand in a particular relation to the conclusion-state. Further, this relation must be such that it makes the reasoning process a correct one. Henceforth, I shall apply the notion of practical reasoning only to correct reasoning (cf., Broome 2002 , p. 87). This means, however, that my definition of practical reasoning I gave above is not entirely correct. Being a process which leads to an intention does not suffice to count as practical reasoning. This process must also be correct.

This invites the question of what is correct practical reasoning. In what follows, I discuss one type of correct practical reasoning which was prominently discussed by Kant. Although Kant himself does not account for its correctness, I think such an explanation can be given. However, this explanation has significant consequences for (i) a general theory of practical reasoning and (ii), in particular, for what might be called "normative practical reasoning", as I shall discuss in Section 3.

\subsection{Explaining the Correctness of Practical Reasoning}

In the Groundwork of Metaphysics of Morals, Kant presents us with what he takes to be one type of correct practical reasoning. Kant writes:

Who wills the end, wills (so far as reason has a decisive influence on his actions) also the means which are indispensably necessary and in his power. (Kant 1948, pp. 80-1)

By reading "will" as "intend" (cf., Broome 2000, p. 197; also see Audi 1989, p. 73) Kant's remark is undoubtedly about correct practical reasoning. Suppose you intend to attend the moral philosophy seminar and a necessary means for you to do so is to be at the philosophy faculty at $4.30 \mathrm{pm}$. If you then do not form an intention to be at the philosophy faculty at $4.30 \mathrm{pm}$, it seems you are not entirely as you ought to be. This is why Kant's remark seems to encapsulate correct practical reasoning. That is, correctness implies that if the premise-states of a correct practical inference are a (part of a) true description of your mental states, but the required conclusion is not, then you are not entirely as you ought to be. I will take this to be the meaning of correctness.

From my argument in Section 1 it follows that it is a virtue of Kant's view that he construes the relation between the premises and the conclusion is a defeasible one. If you intend to obtain $E$ and $A$ is a necessary means to obtain $E$, either you will also intend $A$ or be irrational. But as it stands, Kant's remark is not quite correct. As von Wright observes, even if both premises are true (i.e., you intend $E$ and $A$ is a necessary means to obtain $E$ ), it does not follow that you intend to $A$, even if you are rational (von Wright 1978, pp. 48 
9). You may, for instance, not believe that $A$ is a necessary means to obtain $E$. Therefore, Kant's remark must be slightly adjusted (cf., Broome (2000, p. 197). He should have said "who wills the end, wills the means which he believes to be indispensably necessary". Once adjusted, Kant's view seems (more or less) faultless. ${ }^{10}$

Unfortunately, Kant does not account for why intending the means you believe to be necessary to your intended ends is correct practical reasoning. He only says that his remark is analytically true (Kant 1948, p. 81). That is, taking the means you believe to be necessary to your intended end is part of the meaning of being rational, but this can hardly count as an explanation of why this type of reasoning is correct (Broome 2000, p. 197).

Why then is this type of means-to-end reasoning correct? John Broome provides, I believe, a successful explanation of its correctness (in particular, cf. Broome 2000; 2002). Suppose you reason as follows ${ }^{11}$ :

I am going to attend the moral philosophy seminar.

In order to attend the moral philosophy seminar, a necessary means is to be at the philosophy faculty at $4.30 \mathrm{pm}$.

SO

I shall be at the philosophy faculty at $4.30 \mathrm{pm}$.

You might run through this process of reasoning when deliberating how to spend your afternoon given your intention to attend the moral philosophy seminar. In this case, (1a) expresses one of your intentions and (1b) expresses a belief of yours; both of which lead you to (1c), which expresses your intention to be at the philosophy faculty at $4.30 \mathrm{pm}$.

In his explanation of the correctness of this type of reasoning, Broome assumes that your intentions and beliefs are propositional attitudes which reflect a distinctive posture you take towards propositions (Broome 2002, p. 87). Believing something is to have a truth-taking attitude towards a proposition. Intending something is to have a truth-making attitude towards a proposition. Supposing that your name is Ralph and "I" ("you intend that") and "B"("you believe that") are attitude-operators on propositions, your reasoning in (1) can be described as follows:

$$
\text { and }
$$

I (Ralph will attend the moral philosophy seminar)

B (For Ralph to attend the moral philosophy seminar, a necessary means is to be

at the faculty at $4.30 \mathrm{pm}$ )

leads to

I (Ralph will be at the faculty at $4.30 \mathrm{pm}$ ).

Keeping Kant's remark in mind, it ought to be clear that is only a description of your reasoning and not an inference. From the fact that $(2 a)$ and $(2 b)$ are both true descriptions of your mental attitudes it does not follow that $(2 \mathrm{c})$ will also be a true

\footnotetext{
${ }^{10}$ I say "more or less" because one could argue that Kant's remark is still not entirely correct. Suppose Linda (a philosophy student) intends to get an "A" grade on her final exam paper. She believes that a necessary means to get an "A" grade is that her lecturer reads her exam paper. However, if Linda believes that this will happen even without her intending it, it seems that Linda is not required to intend that her lecturer reads her exam paper (cf., Broome 2002, pp. 90-2).

${ }^{11} \mathrm{I}$ borrow the following schema from Broome (2002).
} 
description of your mental attitude. A failure of your rationality may prevent you from intending to be at the faculty at 4.30 pm (cf., Broome 2002, pp. 87-8).

Because intentions and beliefs are propositional attitudes, you may take a different stance towards the propositions as expressed in (2). For example, instead of intending to be at the faculty at $4.30 \mathrm{pm}$, reasoning may take you to the belief that you will be at the faculty at $4.30 \mathrm{pm}$. Your belief may be based on (3a) and (3b) in which case you run through the following reasoning process:

$$
\begin{aligned}
& \text { B (Ralph will attend the moral philosophy seminar) } \\
& \text { and } \\
& \text { B (For Ralph to attend the moral philosophy seminar, a necessary } \\
& \text { means is to be at the faculty at } 4.30 \mathrm{pm} \text { ) } \\
& \text { leads to } \\
& \text { B (Ralph will be at the faculty at } 4.30 \mathrm{pm} \text { ). }
\end{aligned}
$$

In this case, your reasoning ends in a belief. Again, this is not an inference. You may fail to reason to a belief that you will be at the faculty at $4.30 \mathrm{pm}$, if you are irrational.

For a moment, let us just concentrate on the content of your reasoning:

Ralph will attend the moral philosophy seminar and

For Ralph to attend the moral philosophy seminar, a necessary

means is to be at the faculty at $4.30 \mathrm{pm}$.

Therefore

Ralph will be at the faculty at $4.30 \mathrm{pm}$.

These propositions stand in a particular relation to each other, i.e. (4c) cannot be false if (4a) and (4b) are both true. Consequently, this syllogism constitutes a valid inference. ${ }^{12}$ By comparing the contents of (2) and (3), it follows that this holds for the contents in both reasoning types, for their contents are exactly the same. Thus, the difference between (2) and (3) only lies in "the attitude you take towards the content" (Broome 2002, p. 89). This fact allows Broome to explain the correctness of (2) as follows:

The difference between (2) and (3) is not in their content but in the attitude you take towards their content. For instance, in the belief reasoning (3) your attitude towards the proposition (4a) is to take it as true, whereas in the intention reasoning (2) your attitude is to be set to make this proposition true. In (3) you take (4a) and (4b) as true. Because (4) is a valid inference, if (4a) and (4b) are true, $(4 \mathrm{c})$ must also be true. So you cannot rationally take $(4 \mathrm{a})$ and $(4 \mathrm{~b})$ to be true without taking (4c) as true. This is why (3) is correct belief reasoning. In (2) you take (4b) as true, and are set to make (4a) true. Because (4) is a valid inference, if (4a) and (4b) are true, (4c) must also be true. So you cannot

\footnotetext{
${ }_{12}$ Regarding the validity of this inference, premise ( $\left.3 b\right)$ is certainly stronger than it needs to be. If ( $3 b$ ) were a simple material conditional, the inference would still be valid (Broome 2002, p. 89).
} 
rationally be set to make (4a) true, and take (4b) as true, without being set to make $(4 \mathrm{c})$ true. That is why (2) is correct intention reasoning.

In short, the correctness of reasoning from intending an end to intending the means one believes to be necessary is ensured by the logical relations that hold between the contents of your attitudes. It is correct because the propositions constituting the content of your reasoning entail each other. Consequently, the contents of the propositions you take a certain attitude towards, require of you to form corresponding attitudes towards the entailed proposition. The fact that you are required to do so makes the reasoning described in (2) correct practical reasoning.

\subsection{Scepticism about Practical Reasoning}

David Hume famously declared that "reason alone can never produce any action, or give rise to volition" (Hume 1978, p. 414). Hume thought that reasoning is only concerned with the truth of either mathematical propositions or empirical matters of fact (Hume 1978, p. 413). However, by accepting Hume's dictum, one must not deny that reasoning can be practical. This should be clear from the explanation in 2.1. Truth can be transmitted in two different ways, i.e., by the truth-taking attitude (believing) and the truth-making attitude (intending). So even if reasoning is only concerned with truth, it can "transmit the truth-making stance as well as the truthtaking stance" (Broome 2002, p. 89; see also Broome 2000, p. 199). It can lead to a new belief or a new intention. So reasoning can be genuinely practical.

Consequently, Broome's explanation succeeds in overcoming widespread scepticism that reasoning cannot be practical. However, invoking logical relations involves a minor and a major drawback. The minor drawback is due to the fact that logical relations that hold between the contents of attitudes are not sufficient to determine the correctness of practical reasoning. Suppose you intend to go to the moral philosophy seminar and you believe that if you go to the seminar you will listen to a philosophy paper. However, to reason correctly, you are not required to intend (i.e., being set to make it the case) that you will listen to a philosophy paper. For (I assume) you believe that this will happen anyway. In consequence, "not all putative intention reasoning whose content is a valid inference is correct” (Broome 2002, p. 92; also, cf. Kamm 2000).

Accordingly, logical relations may only be taken as necessary to prove the correctness of reasoning. This assumption, however, involves the major drawback. For it implies that the scope of practical reasoning is extremely limited. Only instrumental reasoning in which you take the means to be strictly necessary to your end will be correct. However, reasoning of this type is rare. Normally we do not believe that a particular means is strictly indispensable. Rather, we find ourselves in a situation where we can choose between different means to attain our ends. For example, you intend to be at the philosophy faculty at $4.30 \mathrm{pm}$ and you believe that if you start walking at $4 \mathrm{pm}$, you will be at the faculty at $4.30 \mathrm{pm}$. So you intend to start walking to the faculty at $4 \mathrm{pm}$. Whilst starting to walk at $4 \mathrm{pm}$ is a sufficient means to your end, it is clearly not necessary. Walking at $3.45 \mathrm{pm}$ would also get you to the faculty on time.

Anthony Kenny argues that instrumental reasoning from intending an end to intending the means one believes to be sufficient is correct practical reasoning 
(Kenny 1975, ch. 5). But it cannot be correct if correctness requires the contents of the premise-states to entail the content of the conclusion state. Looking at the contents of this inference, it not only fails to find support in logic, it finds the condemnation of $\operatorname{logic}^{13}$ (Piller 2001, p. 201).

In sum, the view that reasoning is correct only if its content forms a valid inference implies that practical reasoning is a very limited concept. Even if one may not be justified in being a sceptic about practical reasoning in general, it seems possible to remain sceptical about the correctness of many types of practical inferences which have an intuitive appeal. ${ }^{14}$

In the next section, I therefore discuss alternative methods to ground the correctness of practical reasoning. My discussion will concentrate on normative practical reasoning (i.e., reasoning from a normative belief to an intention). Normative practical reasoning does not find support in logic, but nonetheless seems intuitively appealing. In the end, however, I will remain sceptical that it represents correct practical reasoning.

\section{Normative Practical Reasoning}

Normative practical reasoning is reasoning which sets out from a normative belief and concludes in an intention. The paradigm example of this form of reasoning is reasoning from your belief that you ought to $\phi$ to an intention of yours to $\phi$.

This type of practical reasoning is particularly significant for moral philosophy. First, moral reasoning often leads us (I assume) to beliefs about what you ought to do. Normative practical reasoning then concerns the process of how our normative beliefs become practical through reasoning. Second, if normative practical reasoning could be shown to be correct, it would give moral philosophy an authoritative means to demonstrate that the amoral person is not entirely as she ought to be.

As I argued in Section 1, the (possible) existence of an amoral person is normally taken in support of the thesis that intentions and normative beliefs are not necessarily connected (cf., Dancy 1993, ch. 1). For an amoral person holds distinct beliefs about what she ought (or ought not) to do, but remains to be appropriately motivated by her beliefs (cf., Dancy 1993, p. 4). However, given that it is possible to form an intention based on a normative judgement, ${ }^{15}$ normative practical reasoning can fill the gap between normative beliefs and intentions.

In Section 2, I argued that the correctness of instrumental reasoning can be explained by highlighting a particular relation that holds amongst its contents. Unfortunately, the same cannot be done for normative practical reasoning. Its contents ("I ought to $\phi$ " and "I will $\phi$ ") do not entail each other. Therefore, any assumption that reasoning can be correct only if its content forms a valid inference will reject the correctness of normative practical reasoning straightaway.

However, forming an intention on the basis of believing that one ought to $\phi$ does not seem irrational. To support this claim, one may consider the special meaning of

\footnotetext{
${ }^{13}$ As Kenny notices, the contents of this inference represent the fallacy of affirming the consequent (cf. Kenny 1975, p. 70).

${ }^{14}$ This seems to be the position of a Humean, i.e., someone who thinks that practical reasoning can only be instrumental. (cf. Millgram 1995 and Gauthier 1986).

${ }^{15}$ On this possibility see Broome (2001, pp. 187-93).
} 
"ought" and argue that the content of this normative belief entails that forming an intention upon it constitutes correct reasoning (cf., Piller (2001, p. 200). So, one might after all doubt that logical validity is a necessary property that holds between the contents of correct practical inferences. That is to say, as I remarked in 2.2, it is not only the case that not all practical reasoning whose content forms a valid inference is correct (Broome 2002, p. 92); in addition, it might also be that not all practical reasoning whose content forms an invalid inference is incorrect. Other means than the logical relationship of the contents of a piece of practical reasoning may establish the correctness of a practical inference.

The most promising method to assign correctness to non-instrumental practical reasoning, I think, is to construe correctness analogous to pragmatic justifications in epistemology. Some pragmatists argue that even if the content of your perception $P$ speaks strongly against the content of your belief $B$, having this belief may be justified if it promotes a further (or higher-level) end (such as increasing your wellbeing). In this sense, intending what you believe you ought to do may be the best means to do what you (in fact) ought to do. Clearly, doing what you believe you ought to do will not always lead you to do what you ought to do. This will be so if your belief is false; yet not doing what you believe you ought to do or doing what you believe you ought not do could hardly be a plausible rule of practical reasoning (cf., Piller 2000, p. 209).

In sum, a practical inference may not be incorrect if its contents display an invalid inference. However, even if in general one might succeed in establishing alternative criteria of correctness, I doubt that this can be done for normative practical reasoning - at least when applying the notion of correctness as defined in 2.1. That is to say, from believing that you ought to help your neighbours and yet not intending to do so, it does not necessarily follow that you are not entirely as you ought to be. I argue that correct instrumental reasoning may defeat the claim that you are required to intend to do what you believe you ought to do.

To be sure, by assuming again that your name is Ralph, the question at stake is whether the reasoning from $(5 \mathrm{a})$ to $(5 \mathrm{~b})$ constitutes correct practical reasoning:

B (Ralph ought to help his neighbours)

so

I (Ralph will help his neighbours).

I claim the following argument shows that this inference is not correct. Suppose that you, Ralph, are an evil person. That is to say, you not only hold sincere beliefs about what you ought to do and fail to be motivated by them (as the amoral person); but in addition, the reason why your beliefs do not motivate you is because you believe that you ought to do it. As an evil person, "you are attracted by evil for its own sake" (Dancy 1993, p. 4). That is, your believing that you ought to $\phi$ represents a conclusive reason for you not to $\phi$.

As evil Ralph, you might reason as follows: you intend to be evil and you believe that in order to be evil a necessary means is not to do what you ought to do. Correct instrumental reasoning consequently leads you to the intention not to do what you believe you ought to do. Clearly, you might be wrong otherwise. Perhaps you ought not to intend to be evil in the first place and hence ought not to intend to do what you believe you ought to do. But it should be clear that this does not affect the correctness 
of the reasoning process as such. ${ }^{16}$ Correctness of instrumental reasoning stems solely from the valid inference that is formed by its content and not from whether you ought to (or have a reason to) be in these states. So the process of your reasoning will be correct.

In order to determine what to do, you (the evil Ralph) reason as follows:

$$
\begin{aligned}
& \text { I (Ralph will be evil) } \\
& \text { and }
\end{aligned}
$$

B (For Ralph to be evil, it is a necessary means not to do what

he ought to do). so

I (Ralph will not do what he ought to do). and

$$
\begin{aligned}
& \text { B (Ralph ought to help his neighbours). } \\
& \text { so } \\
& \text { I (Ralph will not help his neighbours). }
\end{aligned}
$$

As outlined above, (6a) to (6c) constitutes correct instrumental reasoning. That is, $(6 \mathrm{c})$ is required by (6a) and (6b). Furthermore, (6c) and (6d) require (6e); if you intend not to buy what your wife told you to buy and you believe that she told you to buy red socks, correct reasoning will lead you to intend not to buy red socks. So reasoning from (6c) and (6d) to (6e) will also be correct. However, considered on its own, (6d) requires of you not to intend (6e). It requires of you to have the contrary intention, i.e. to help your neighbours.

As a result, instrumental reasoning and normative practical reasoning can lead to a practical inconsistency in the form of incompatible intentions, even though the premises of this reasoning process are not incompatible. Both types of reasoning can simultaneously require of you to adopt a truth-making attitude towards a proposition and its negation. Thus, both cannot be types of correct reasoning. Since the correctness of instrumental reasoning in which you take the means to your end as strictly necessary seems to have strong support on its side, I claim that it is normative practical reasoning which has to go. Therefore, I remain sceptical about whether correct reasoning requires of you to form an intention to $\phi$, if you believe you ought to $\phi$.

In summary, practical reasoning is a mental process which takes a person from her existing mental states to an intention. One way to establish the correctness of a practical inference is to show that the contents of the mental states form a valid inference. However, discovering such a relation does not suffice to show that a practical inference is correct. Furthermore, if a piece of practical reasoning contains a normative proposition (such as "I ought to $\phi$ ) it is arguably not even necessary that its content forms a valid inference to establish its correctness.

However, I showed that in the case of normative practical reasoning the prospect of establishing that a person is required to intend what she believes she ought to do looks rather dim. An inference from believing that you ought to $\phi$ to your intention to $\phi$ can be defeated by correct instrumental reasoning.

\footnotetext{
${ }^{16}$ For an explanation of why this does not affect the correctness of practical reasoning, see Broome (1999, esp. pp. 411-3).
} 
As a result, normative practical reasoning fails to show why an amoral person is not entirely as she ought to be. Turning evil seems to suffice to defeat the requirement that you intend to do what you believe you ought to do.

Acknowledgments I am very grateful to audiences at Budapest, Cork, and Warwick, and to an anonymous referee of Acta Analytica for helpful comments on earlier drafts of this paper. This paper was written with financial support of the Austrian Academy of Sciences. I thank the Academy for its generous support.

\section{References}

Aristotle. (1978). De Moto Animalium, trans. M.C. Nussbaum. Princeton: Princeton University Press. Audi, R. (1989). Practical Reasoning. London and New York: Routledge.

Broome, J. (1997). Reason and Motivation. Aristotelian Society Supplementary, Volumes, 71, 131-46.

Broome, J. (1999). Normative Requirements. Ratio, 12, 398-419.

Broome, J. (2000). Instrumental Reasoning. In J.Nida- Rümelin and W. Spohn (eds.), Rationality, Rules and Structure. Kluwer, 195-207

Broome, J. (2001). Normative Practical Reasoning. Proceedings of theAristotelian Society Supplementary, Volumes, 75, 175-93.

Broome, J. (2002). Practical Reasoning. In J. L. Bermúdez \& A. Millar (Eds.), Reason and Nature: Essay in the Theory of Rationality (pp. 85-111). Oxford: Clarendon Press.

Dancy, J. (1993). Moral Reasons. Blackwell: Oxford and Cambridge (Mass.)

Gauthier, D. (1986). Morals by Agreement. Oxford: Clarendon Press.

Hume, D. (1978). A Treatise of Human Nature. L.A. Selby-Bigge and P.H. Nidditch (eds.). Oxford: Oxford University Press.

Kamm, F. (2000). The Doctrine of Triple Effect and why a Rational Agent needs to Intend the means to his end. Proceedings of the Aristotelian Society Supplementary, Volumes, 74, 21-39.

Kant, I. (1948). Groundwork of the Metaphysics of Morals, trans. H.J. Patron. London: In The Moral Law, Hutchinson.

Kenny, A. (1975). Will, Freedom and Power. Oxford: Blackwell.

Lewis, D. (1989). Dispositional Theories of Values. Proceedings of the Aristotelian Society, Supplementary Volumes, 63, 113-37.

Millgram, E. (1995). Was Hume a Humean? Hume Studies, 21, 75-93.

Parfit, D. (1997). Reasons and Motivation. Proceedings of the Aristotelian Society, Supplementary Volumes, 71, 99-130.

Piller, C. (2000). Doing What is Best. The Philosophical Quarterly, 50, 208-26.

Piller, C. (2001). Normative Practical Reasoning. Proceedings of the Aristotelian Society, Supplementary Volumes, 75, 195-216.

Raz, J. (1978), (ed). Practical Reasoning, Oxford: Oxford University Press

Smith, M. (1994). The Moral Problem. Blackwell: Oxford and Cambridge (Mass.)

Stocker, M. (1979). Desiring the Bad: An Essay in Moral Psychology. Journal of Philosophy, 76, 738-753.

Vogler, J. (2001). Anscombe on Practical Inference. In E. Millgram (Ed.), Varieties of Practical Reasoning (pp. 434-464). Cambridge: MIT Press.

von Wright, G. H. (1978). On So-called Practical Inference. In J. Raz (Ed.), Practical Reasoning (pp. 4662). Oxford: Oxford University Press. 